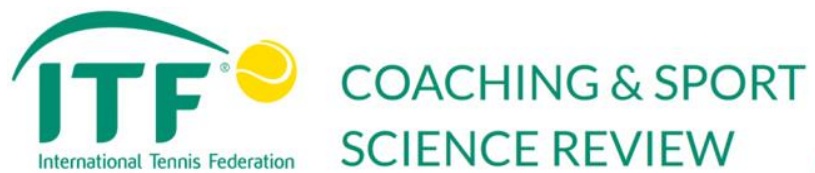

International Tennis Federation

www.itfcoachingreview.com

August 2019. 27th Year. Issue 78. 29-31

ISSN 2225-4757

https://doi.org/10.52383/itfcoaching.v27i78.91

\section{Mini-Ballschool for children 3 to 6 years old}

\author{
Michael Ebert ${ }^{a}$ \\ ${ }^{a}$ Ballschool Heidelberg, Vienna, Austria.
}

\section{ABSTRACT}

Children are often missing fundamental movement skills and elementary ball skills when they get into the game of tennis. They have not learned to play but they are often specifically trained from the very beginning. Learning is mostly done by practicing with instructions and corrections. The Mini-Ballschool for children 3 to 6 focuses on playing as the elementary form of learning.

\author{
Key words: Fundamental \\ movement skills, ball skills, $A B C$ \\ of learning to play, implicit \\ learning. \\ Received: 12 March 2019 \\ Accepted: 01 May 2019 \\ Corresponding author: Michael \\ Ebert, Ballschool Heidelberg, \\ Steigenteschgasse 154/10 \\ 1220 Vienna, Austria. Email: \\ michael.ebert@aon.at
}

\section{INTRODUCTION}

"Physical activity is an essential factor for the learning process, and has, together with cognition, a crucial function for the children's development. This is why a support of childhood competences emphasizes physical activity in particular." (Ministry of Education and Cultural Affairs of Lower Saxony, 2005, p.18).

The importance of the first years for the development of the child cannot be given enough attention. Toddlers and preschoolers acquire the basis for the ability of learning and building relationships. Varied physical activity and playing are seen as the trigger and engine for the children's holistic development and education. In this regard, it is consistently said that it is in the children's nature to move and play (Club of Cologne, 2003, p.7).

\section{THE "ABC OF LEARNING TO PLAY"}

\section{Training of general motoric competences and -skills}

A comprehensive training of general motor competences and skills is indispensable already at kindergarten. The MiniBallschool that was particularly designed for toddlers and preschoolers, makes a major contribution to a qualified training of basic motoric skills. The programme bears in mind that Mini-Ballschoolers are not specialists at this age but allrounders and playing with different balls in that particular period of development poses enormous challenges. The curriculum combines many ideas and aspects especially of kinesiology, exercise science and sports psychology (Roth, et. al, 2018). The Mini-Ballschool that has been tested and proved successful in kindergartens and clubs for many years, is based on the concept of Ballschool Heidelberg that was founded by Prof. Dr. Klaus Roth in 1998.

The Mini-Ballschool's basic principles and goals

There are three generally accepted key principles of the MiniBallschool. First, the goals need to be adapted to the children's developmental stage. Second, the contents are to ensure joyful learning. And third, the method chosen should be noninstructed "free play".

"Starting with children from where they are" is fundamental. This means that regard must be given to the movement competences toddlers and pre-schoolers usually have and that also the children's individual talents have to be taken into account (Roth, et. al, 2018). Two of the main considerations at the beginning were: What are kindergarten children really capable of? And what skills can be trained especially well?

The Mini-Ballschool defines three pillars, similar but also different to the "ABC of learning to play", the successful Ballschool Heidelberg programme for primary school children. Pillar A refers to the fundamental movement skills. Pillar B focuses on basic technical-tactical competences. Pillar $C$ deals with basic coordination competences. The Mini-Ballschool's letters A, B, C become the "ABC of learning to play" for toddlers and pre-schoolers (Roth, et. al, 2018).

Pillar A: basic movement skills

At early toddler age, normally developed children have already gained fundamental movement skills, such as walking, running, or bouncing. Building on this, other skills such as 
throwing, hitting and kicking can be taught. Such fundamental movement skills are often also called phylogenetic skills. They are part of the repertoire of normally developed children at kindergarten age and are acquired across cultures (Roth, et. al, 2018). At pre-school age, another development step can be observed: all basic movement skills are increasingly optimized. The execution of movements is more stable (stability), can be better adapted to respective situations (variability) and requires less effort and attention (automation). At the age of 5 to 6 children are able to differentiate fundamental movement skills and to combine these skills fluently (Keller \& Meyer, 1982).

There are seven basic movement skills that are taught and optimized with the Mini-Ballschool's pillar A. Mastering these fundamental movement skills is a required minimum for the successful participation in various physicalathletic activities, not only in playing. They are fundamental for the teaching of basic technicaltactical skills in pillar B. And also the acquisition of basic coordination abilities in pillar $C$ would not be possible (Roth, et. al, 2018).

Table 1 shows the selection of the fundamental movement skills (pillar A) that focuses on the children's developmental stage and the central orientation in playing with balls.

Pillar B: basic technical-tactical skills of primary school age, children are already equipped with about $80 \%$ of their final performance level.

Table 1 shows the selection and the five concrete objectives of pillar $C$ which follow current knowledge of kinesiology (see Neumaier \& Mecheling, 1995; modified by Roth, 1998) and coincide with the typical criteria for coordination performances: speed, precision, complexity, organization and variability.
Preschool age offers children not only to learn and optimize fundamental movement skills, but also to learn first basic tactical and technical skills which are characteristic for many sports games. These skills, called ontogenetic skills, are based on the phylogenetic repertoire and are no longer learned by all children, but have to be acquired individually (Burton \& Miller, 1998, p. 59).

But there is a clear no-go in the Mini-Ballschool as was well as in the Ball-School programme for primary school children. It is not about teaching specific technical skills and it is not about acquiring tactical knowledge for specific sports games. According to Wittgenstein (1960) the idea of the Ballschool Heidelberg is that all sports games are something like family members. Of course there are specific peculiarities but a number of technical and tactical motor tasks can be found across more or less all sports games (Haverkamp \& Roth, 2006).

Table 1 shows the selection of six general technical-tactical skills (pillar B) that seem to be appropriate for the children's performance level and their learning ability.

\section{Pillar C: basic coordination abilities}

Coordination abilities refer to the control and regulation of movements. At toddler- and preschool age, the development of coordination abilities is, because of the early growth of the central nervous system, by far the most advanced. At the end
Table 1: Mini-Ballschool's $A B C$

\section{The Mini-Ballschool's contents}

"While playing a child is learning. However, it never plays in order to learn but because it finds enjoyment in what it is doing" (Zimmer, 2004, p.89). Children experience their environment, playing. The Mini-Ballschool's contents mostly consist of games and distinguishes three forms of playing (Roth, et. al, 2018):

- $\quad$ Free play (non-instructed)

- $\quad$ Playing with given (external) stimuli

- Task-oriented playing

Free play usually takes place in activity landscapes, where the placement of the different material allows children to play without any external instructions. Playing with given (external) stimuli means that Mini-games are integrated into imagery stories where the children play different roles. Playing task-oriented means that children receive precise instructions and also the tasks of the children are determined.

Playing is the elementary form of learning for children because of a neurotransmitter in the human brain: dopamine. Dopamine is released when a child, having completed a motor task, achieves better results than expected. Mini-games therefore have to effect mainly one thing: an unexpected sense of achievement, preferably as often as possible. 
Successful movement patterns are memorized by the human brain via dopamine (Beck, 2013a, b).

\section{The Mini-Ballschool's methods}

"Never help a child with a task at which he feels he can succeed" (Maria Montessori, 1870-1952).

Without doubt it is important that children discover and experience as many things as possible on their own. The natural form of playing in the Mini-Ballschool is free play which allows children to actively discover things. This approach supports children to create their learning processes on their own without being instructed or corrected all the time. Learning is possible by practicing (explicit learning) but it is also possible to acquire knowledge or skills incidentally without any effort (Roth, et. al, 2018). Learning without being conscious of the fact that we are learning at that specific moment is called implicit learning and fundamental for the Mini-Ballschool's methods. This means that children do not have to gain conscious knowledge of solving general movement or tactical problems. Much more they have to increasingly act appropriately to the situation because of their acquired versatile playing-experience.

\section{CONCLUSION}

The Mini-Ballschool does not only contribute to an active childhood but its physical activities help to improve motor performances, health as well as the cognitive and psychological development. The contents and methods as well as the three pillars of the Mini-Ballschool that focus on the improvement of fundamental movement skills (A), basic technical-tactical skills (B) and basic coordination abilities (C), provide a unique and valuable guide for the work with children at toddler and pre-school age. Equipped with these playfully acquired skills the step into tennis will be joyful one because they have learned to play before they get trained.

\section{REFERENCES}

Beck, F. (2013a). Dopaminsport - Hirnforschung zur Optimierung des sportlichen Trainings und Förderung kognitiver Leistungen für Schule und Verein. Unveröffentlichtes Manuskript.

Beck, F. (2013b). Förderung exekutiver Funktionen in kleinen Sportspielen in der Grundschule - Hirnforschung zur Optimierung des sportlichen Trainings und Förderung kognitiver Leistungen für Schule und Verein. Unveröffentlichtes Manuskript.

Burton, A. W. \& Miller, D. E. (1998). Movement Skill Assessment. Champaign: Human Kinetics.

Club of Cologne (2003). Consensus-Erklärung der 3. Konferenz des

Club of Cologne. In Club of Cologne (Hrsg.), Bewegungsmangel bei

Kindern: Fakt oder Fiktion? (S. 6-9). Hamm: Achenbach.

Haverkamp, N. \& Roth, K. (2006). Untersuchungen zur Familienähnlichkeit der Sportspiele. Bielefeld/Heidelberg: Universität.

Keller, H. \& Meyer, H.J. (1982). Psychologie in der frühen Kindheit.

Stuttgart: Kohlhammer.Neumaier, A. \& Mechling, H. (1995). Taugt das Konzept koordinativer Fähigkeiten als Grundlage für sportartspezifisches Koordinationstraining? In P. Blaser, K. Witte \& C. Sucke (Hrsg.), Steuer- und Regelvorgänge der menschlichen Motorik (S. 207-212). St. Augustin: Academia.

Niedersächsisches Kultusministerium (2005). (Hrsg.).
Orientierungsplan für Bildung und Erziehung im Elementarbereich Niedersächsischer Tageseinrichtungen für Kinder. Hannover: Eigendruck.

Roth, K., Roth, Ch. \& Hegar, U. (2018). Mini-Ballschool. The "ABC of learning to play" for toddlers and pre-schoolers. Schorndorf: Hofmann.

Wittgenstein, L. (1960). Philosophische Untersuchungen. Schriften, Band 1. Frankfurt: Akademie.

Zimmer, R. (2004). Handbuch der Bewegungserziehung (20. Gesamtauflage). Freiburg: Herder.

\section{RECOMMENDED ITF TENNIS ACADEMY CONTENT (CLICK BELOW)}

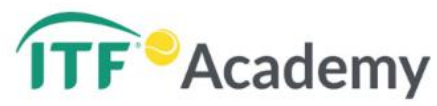

Copyright (c) 2019 Michael Ebert

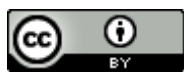

This text is under a Creative Commons BY 4.0 license

You are free to Share - copy and redistribute the material in any medium or format - and Adapt the content - remix, transform, and build upon the material for any purpose, even commercially under the following terms:

Attribution: You must give appropriate credit, provide a link to the license, and indicate if changes were made. You may do so in any reasonable manner, but not in any way that suggests the licensor endorses you or your use.

CCBY 4.0 license terms summary CCBY4.0 license terms 